\title{
Technical and Economic Feasibility of Applying Battery Energy Storage for Enabling Voltage Stability of Grid-Connected Photovoltaic Power Systems
}

\author{
Fei Ge ${ }^{1}$, Bin Ye ${ }^{1}$, Xuli Wang ${ }^{1}$, Zhuang Cai ${ }^{2}$, Lei Dai ${ }^{1}$, Bin $\mathrm{Hu}^{1}$ \\ ${ }^{1}$ State Power Economic Research Institute of State Grid Corporation of China; \\ Energywende Smart Tech Limited, Beijing, China.
}

\begin{abstract}
Keywords: distributed solar power, voltage deviation, battery energy storage system, sizing and operation strategy.
\end{abstract}

\begin{abstract}
Voltage stability is considered to be a significant issue due to the increased penetration level of photovoltaic (PV) power generation. The voltage deviation, which occurs normally at the connection point of photovoltaic power generation, is resulted from the non-robust distribution network especially in some Chinese rural area. Battery Energy Storage System (BESS) are increasingly interesting to help integrate solar power into the grid. In this paper, an investigation of technical and economic feasibility will be implemented to propose a cost-effective sizing and operation strategy for distributed BESS in the distribution networks. The cost effectiveness of the BESS will be discussed by numerical simulations of power flow calculation based on hour-by-hour solar power generation, which is related to a typical distribution network in Chinese rural area. The results prove the possibilities of making voltage management in an economical and efficient way.
\end{abstract}

\section{Introduction}

Grid-connected photovoltaic power generation is recently increasing rapidly and resulting in many issues in the field of such as power quality, voltage stability, supply reliability and relay protection for distribution system operators [1]. Specifically, voltage stability is considered to be the most significant due to the increased penetration level of photovoltaic power generation [2]. Beside the inherent intermittency of the solar resource, the voltage deviation is also resulted from the non-robust distribution network especially in some Chinese rural area. Motivated by these facts, a review of current technologies, which can enhance the voltage stability of distribution system, will be classified and evaluated in this paper.

Moreover, BESS are increasingly interesting to help integrate solar power into the grid [3]. The customer-side BESS is capable of load shifting with sub-second response times, in order to prevent the distribution network from inverse power flow. In this paper, an investigation of technical and economic feasibility will be implemented to propose a cost-effective sizing and operation strategy for distributed BESS in the distribution networks. This sizing and operation strategy will be proposed also under consideration of different impact factors of voltage deviation. The cost effectiveness of the BESS will be discussed by numerical simulations of power flow calculation based on hour-byhour solar power generation, which is related to a typical distribution network in Chinese rural area. The results prove the possibilities of making voltage management in an economical and efficient way. This study is also significant important for the utilities such distribution system operators, who is responsible to formulate the integration standards of distributed solar power units.

In [4], a transient modeling of the grid connected solar PV is performed along with Maximum Power Point Tracking (MPPT) algorithm on a Real Time Digital Simulator (RTDS). In [5], an inherent law between voltage deviation and the impact factors is investigated and all the impacts are summarized in [6][7][8][9]. The impact factors of voltage fluctuation can be summarized into three aspects, namely the voltage level of integration point, the installation capacity of photovoltaic generation and different solar resource daily and seasonally. In [10][11], the BESS is proposed as an excellent solution to integrate more solar power in distribution network and an economic and efficient voltage management is implemented by using customer-owned energy storage systems in a 
distribution network with high penetration of photovoltaic systems. In [12][13], a system model that includes a physical battery

model and a voltage regulation and peak load shaving oriented energy management system (EMS) is developed, in order to achieve a cost-benefit optimization considering individual BESS cost with its lifetime estimation.

Nomenclature:

BESS battery energy storage system

BMS battery management system

EAC equivalent annual cost

EMS energy management system

MPPT maximum power point tracking

NPV net present value

PV photovoltaic

RTDS real time digital simulator

\section{Methodology}

\subsection{Theoretical Analysis of Voltage Rises}

In Fig 1, the voltages at both connection point of PV system and distribution network are assumed as $U, U_{s} . R_{s}+j X_{s}$ describes the resistance and impedance of the feeder between PV system and distribution network. $P+j Q$ and $P_{L}+j Q_{L}$ indicate the PV power output and load consumption. The voltage at the load side can be calculated as follows when the PV system is not integrated into the grid.

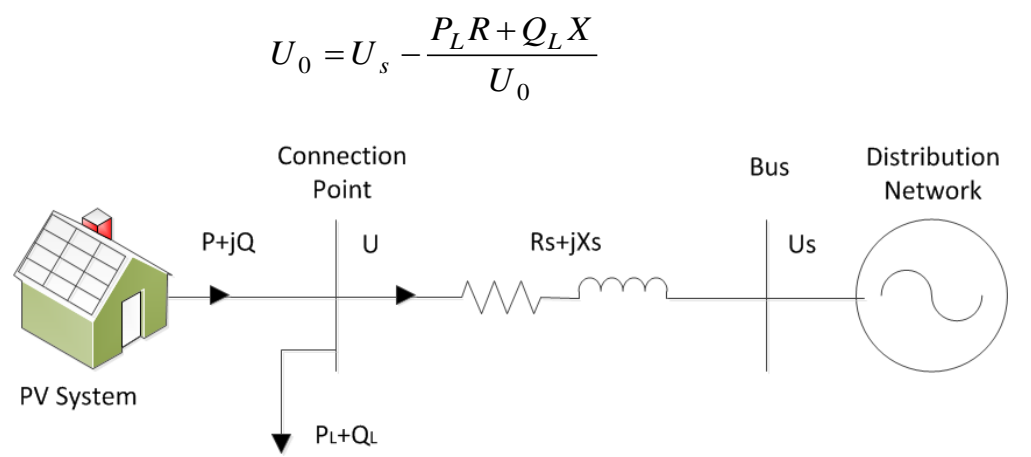

Fig. 1. Thevenin equivalent circuit of grid-connected PV system

However, the voltage $U_{1}$ at the load side is changed when the PV system is integrated into the grid.

$$
U_{1}=U_{s}+\frac{\left(P-P_{L}\right) R+\left(Q-Q_{L}\right) X}{U_{1}}
$$

The voltage variation between the two szenario is calculated as follows.

$$
\Delta U=U_{1}-U_{0}=\frac{P R+Q X}{U_{1}}+\left(P_{L} R+Q_{L} X\right)\left(\frac{1}{U_{0}}-\frac{1}{U_{1}}\right)
$$

The voltage rise is caused by the inverse power flow form PV system and $\left(\frac{1}{U_{0}}-\frac{1}{U_{1}}\right)$ can be considered as a value close to zero. Therefore, the voltage rise at the end of the line with respect to that in the beginning of the feeder can be approximated as follows. The impact factors, which can cause the voltage rise with the integrated PV system in a distribution network, are the active and reactive powers injected by a PV inverter, as well as the resistance and impedance of the feeder.

$$
\Delta U=\frac{P R+Q X}{U}
$$




\subsection{Battery Model}

The operation strategy of battery energy storage system is strongly depending on the voltage rise. A general definition of battery operation status can be represented as Fig 2. Fig 2 shows a block diagram with the input variables (state of charge of last time point and signal of voltage rise) and the output variables (state of charge of current time point, dispatched discharge or charge power and state of health). Moreover, the power and capacity constraints of the battery type are also considered in the general model.

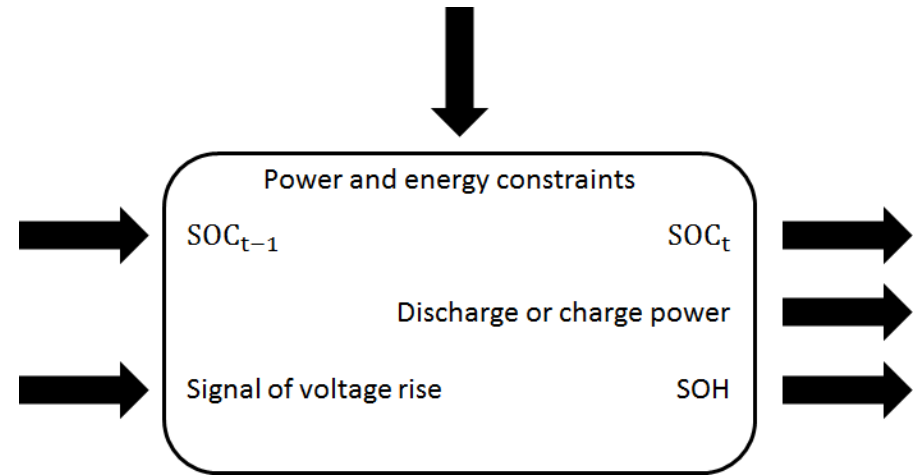

Fig. 2. Block diagram of a general battery model with input and output quantities

The dispatched discharge or charge power is limited by the power and energy constraints of battery energy storage system. The power constraint is determined by the installed converter capacity, while the energy constraint is determined by the installed battery capacity. in addition, total efficiency of a system is defined by the combined efficiency of all system components. In this case, two efficiencies of both battery and converter are described. For an energy storage system, a so-called round-trip efficiency is normally defined, which means the ratio between the energy retrieved and the energy supplied to the system when a charge-discharge cycle is performed between two defined states of charge at a given power level. In general, the performance of a battery depends on its inherent limit and operation conditions. Different battery technologies have also differences in operation performance. Therefore, the difference can be distinguished by different specification of property parameters. An update of SOC in this paper can be shown as follows.

$$
\begin{gathered}
S O C_{t}=S O C_{t-1}+\frac{\left(\eta_{\text {cinv }} \cdot \eta_{c b a t} \cdot P_{c t}-\frac{P_{d t}}{\eta_{\text {dinv }} \cdot \eta_{\text {dbat }}}\right) \cdot T}{E_{\text {rate }}} \\
S O C_{d o w n} \leq S O C \leq S O C_{\text {upper }} \\
P_{\text {down }} \leq P_{c t}, P_{d t} \leq P_{\text {rate }}
\end{gathered}
$$

- $\mathrm{SOC}_{\mathrm{t}}$ : state of charge in time step $\mathrm{t}$

- $\eta_{c_{\mathrm{Liny}}} \cdot \eta_{\mathrm{c}_{\mathrm{b} \text { itt }}}$ : charge efficiency of inverter and battery

- $\eta_{d_{i m y}} \cdot \eta_{d d_{b x z}}$ : discharge efficiency of inverter and battery

- $\mathrm{P}_{\mathrm{a}_{\mathrm{t}}}, \mathrm{P}_{\mathrm{d}_{\mathrm{t}}}:$ charge and discharge power in time step $\mathrm{t}$

- $\mathrm{T}$ : the time period between each time step

- $\mathrm{SOC}_{\mathrm{down}}, \mathrm{SOC}_{\mathrm{upper}}$ : lower limit and upper limit of state of charge

- $\mathbb{P}_{\text {dourm }}, \mathrm{P}_{\text {rate }}$ : lower power limit and rate power capacity of inverter

The charge and discharge power are the optimization parameters. Furthermore, the installed power and energy capacity of the whole battery energy storage system will be also optimized. 


\subsection{Optimization of Sizing and the Operation Strategy For BESS}

In this paper, a so-called two-layer optimization structure is proposed and applied in the simulation and optimization. As shown in Fig 3, the input parameters consist of PV generation curve, load profile, designated power network and economic parameters for the BESS. Firstly, an initial configuration of BESS with a small capacity is proposed for the power flow calculation. Secondly, the net present value of the proposed BESS can be calculated based on a predetermined economic parameter. Thirdly, the simulation results of power flow calculation give the voltage at the connection point of PV system. The iteration is stopped, when the voltage rise can be tolerated within the power grid standards. Otherwise, the BESS capacity is enlarged with an expansion step width. At last, the iteration is stopped, when the voltage rise satisfies the power grid standards and meanwhile the system solution achieves an economic result.

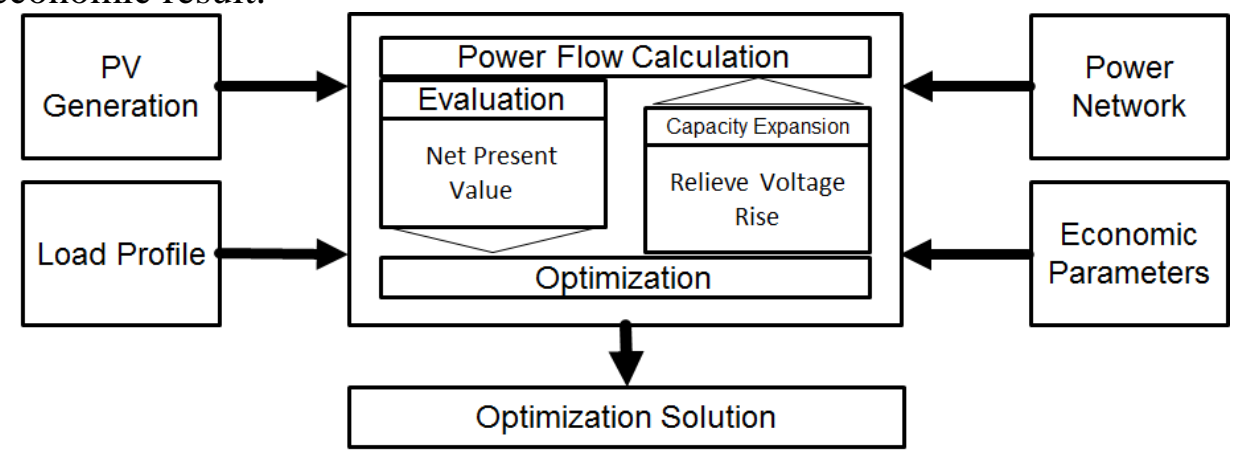

\subsection{Economic Model}

Fig. 3. Two-layer optimization structure

The cost of a BESS such as initial investment, payments of maintenance and operation should be considered in the optimization process. Because the cash flow can be carried out at different time point, the method of equivalent annual cost (EAC) is used to calculate the cost of BESS. The equivalent annual cost stands for the cost per year of owning and operating an asset over its entire lifespan. It can be calculated by dividing the net present value (NPV) of a project by the present value of annuity factor.

$$
\begin{gathered}
E A C=\frac{N P V}{A_{t, r}} \\
A_{t, r}=\frac{1-\frac{1}{(1+r)^{t}}}{r}
\end{gathered}
$$

Where $\mathrm{r}$ is the annual interest rate and $\mathrm{t}$ is the number of years. EAC is often used as a decisionmaking tool in capital budgeting when comparing investment projects of unequal lifespans. Hereby an assumed example is introduced to explain the method of equivalent annual cost:

Table 1. EAC of an assumed example

\begin{tabular}{ccc}
\hline Option & Equipment A & Equipment B \\
\hline Investment & $50,000 €$ & $150,000 €$ \\
\hline Lifetime & 3 years & 8 years \\
\hline Annual maintenance cost & $13,000 €$ & $7,500 €$ \\
\hline Equivalent annual cost & $\frac{50,000}{A_{3,5}}+13,000=31,360 €$ & $\frac{150,000}{A_{8,5}}+7,500=30,708 €$ \\
\hline
\end{tabular}

The EAC is calculated for both cases. The annual interest rate was assumed as 5\%. The results indicate that to invest in equipment $\mathrm{B}$ is better than equipment $\mathrm{A}$, since the $\mathrm{EAC}$ of equipment $\mathrm{B}$ is lower than equipment $\mathrm{A}$. In this paper, the battery energy storage system is divided into battery and converter. The annual maintenance cost, which is a certain percentage of the investment, keeps the same for the whole lifetime. Therefore, the system cost calculation can be represented as follows. 


$$
C_{s y s}=\left(\frac{I_{b a t t}}{A_{t, r}}+M_{b a t t(\%)} \cdot I_{b a t t}+\frac{I_{c o n}}{A_{t, r}}+M_{c o n(\%)} \cdot I_{c o n}\right) \cdot \frac{N_{\text {day }}}{365}
$$

- $C_{s y s}:$ system cost during the simulation period

- $I_{\text {batt }}, I_{\text {mon }}$ : investment of battery and converter

- $A_{\mathrm{t} y}$ : annuity factor, where $\mathrm{t}$ is determined by the calculation of $\mathrm{SOH}$ and $\mathrm{r}$ is the annual interest rate

- $M_{\text {batt(G) }}$ : annual maintenance cost, a certain percentage of the investment

- $N_{\text {day }}$ : the day number of the whole simulation period

\section{Results}

In this paper, only one type of battery technologies, namely lithium ion battery, is used for the simulations. Lithium-ion technology is relatively more expensive due to the high cost of the lithium. However, an increased life expectancy as well as a better efficiency makes it popular. Due to the risk of thermal run-up (Thermal Runaway) an expensive Battery Management System (BMS) has to be carried out, in order to montore the voltage and the temperature of each individual cell. There are considerable cost-cutting potentials in the event of a higher market penetration.

Table 2. Parameters for battery energy storage system

\begin{tabular}{|c|c|c|}
\hline Parameter & Now (2015) & Unit \\
\hline \multicolumn{3}{|l|}{ Lithium-ion battery } \\
\hline Charge efficiency & 97 & $\%$ \\
\hline Discharge efficiency & 97 & $\%$ \\
\hline Investment (cell) & 250 & $€ / \mathrm{kWh}$ \\
\hline Cycle life & $3000 @ 100 \%$ DOD & \\
\hline Calendar life & 15 & year \\
\hline Cost per kWh (peripheral) & 240 & $€ / \mathrm{kWh}$ \\
\hline Lifetime of peripheral & 15 & year \\
\hline Maintenance cost & 1.5 & $\%$ Invest. /year \\
\hline \multicolumn{3}{|l|}{ Converter } \\
\hline Charge efficiency & 97 & $\%$ \\
\hline Discharge efficiency & 97 & $\%$ \\
\hline Investment & 200 & $€ / \mathrm{kWh}$ \\
\hline Lifetime & 20 & year \\
\hline Maintenance cost & 1.5 & $\%$ Invest. /year \\
\hline Interest rate & 4 & $\%$ \\
\hline
\end{tabular}

In this paper, the simulation szenarios can be divided into three categories according to different voltage levels. Namely, the PV systems are connected at $380 \mathrm{~V}, 10 \mathrm{kV}$ and $35 \mathrm{kV}$ bus. The power networks are described as follows. In Fig 4, the left figure (scenario 1) shows the PV system in an area is connected at the $380 \mathrm{~V}$ bus, while the load is in B area. The middle figure (scenario 2) shows the PV system in D area is connected at the $10 \mathrm{kV}$ bus, while the load is in C area. The right figure 
(scenario 3) shows the PV system in E and F area is connected at the $35 \mathrm{kV}$ bus, while the load is in $\mathrm{G}$ area. The allowed voltage deviation and load capacity in each scenario is shown in Table 3.
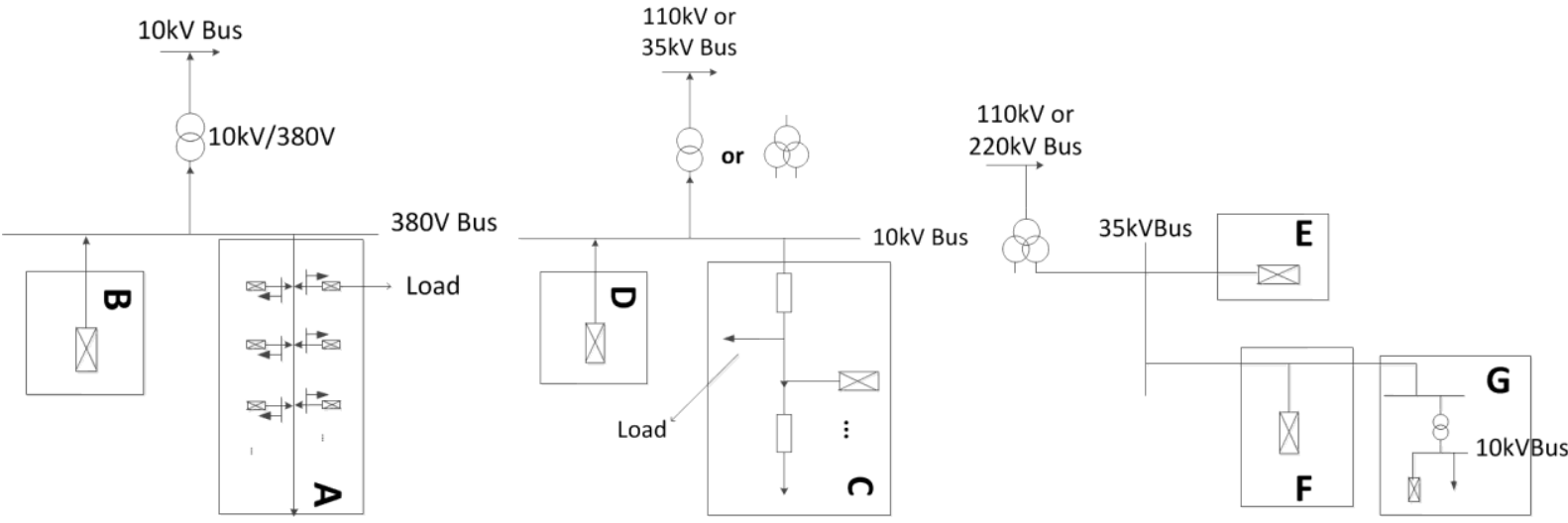

Fig. 4. Power network in different scenarios

Table 3. The allowed voltage deviation and load capacity for different scenarios

\begin{tabular}{cccc}
\hline Scenario & Voltage level & Voltage deviation & Load capacity \\
\hline 1 & $380 \mathrm{~V}$ & $7 \%$ & $50 * 0.6 \mathrm{~kW}$ \\
\hline 2 & $10 \mathrm{kV}$ & $5 \%$ & $5 * 0.8 \mathrm{MW}$ \\
\hline 3 & $35 \mathrm{kV}$ & $3 \%$ & $3 * 5 \mathrm{MW}$ \\
\hline
\end{tabular}

Based on the proposed two-layer optimization structure, the optimized BESS capacity is shown in Table 4 in different scenarios. According to the results, the demand of BESS capacity increases significantly along with an increasing of voltage level. Therefore, the EAC increases due to a large BESS capacity. The ratio between power and energy capacity of BESS in theses scenario is irregular.

Table 4. Optimized capacity and the cost accordingly

\begin{tabular}{cccc}
\hline Scenario & Power capacity & Energy capacity & EAC \\
\hline 1 & $15 \mathrm{~kW}$ & $14 \mathrm{kWh}$ & $373 \$ /$ Year \\
\hline 2 & $0.5 \mathrm{MW}$ & $2 \mathrm{MWh}$ & $9552 \$ /$ Year \\
\hline 3 & $2.5 \mathrm{MW}$ & $1 \mathrm{MWh}$ & $47761 \$ /$ Year \\
\hline
\end{tabular}

\section{Conclusion}

Integration of energy storage systems into the smart grid to manage the real power variability of solar by providing rate variation control can optimize the benefits of solar PV. Using the BESS to provide voltage stability can reduce integration challenges associated solar PV. Coupling solar PV and storage will drastically increase reliability of the smart grid, enables more effective grid management, and creates a dispatchable power product from as-available resources. The rapidresponse characteristic of the BESS makes storage especially valuable as a regulation resource and enables it to compensate for the variability of solar PV generation. Battery energy storage systems can also improve the economics of distributed solar power generation by reduced need for cycle traditional generation assets and increasing asset utilization of existing utility generation.

In this paper, the two-layer optimization structure is proposed to optimize the power and energy capacity of BESS. The results indicate that an increasing voltage level for the connection point can cause an increasing demand of BESS. Therefore, the cost of BESS can increase accordingly. Although this is by far not representative, it is worth nothing that the BESS system was capable to reduce the voltage deviation. We can therefore conclude that coupling PV with a BESS could help to establish a new voltage stability and a new understanding of how renewable energy resource can generate electricity into the power grid in the future.

The focus in this paper was to figure out the technical and economic feasibility of applying battery energy storage for enabling voltage stability of grid-connected photovoltaic power systems. The effect of battery aging will be considered in next step together with a longer period simulation in 
order to provide more representative optimization results. Because of the robustness and ability to extend the two-layer optimization structure, the simulation tool can be added with more elements such as wind generation or diesel generation as next step in this study.

\section{References}

[1]. Al-Abri R. Voltage Stability Analysis with High Distributed Generation (DG) Penetration[J]. 2012.

[2]. F. Katiraei and J. R. Agüero, "Solar PV integration challenges,” IEEE P\&E Mag., vol. 9, no. 3, pp. 62-71, May-Jun. 2011.

[3]. Dunn B, Kamath H, Tarascon J M. Electrical energy storage for the grid: a battery of choices[J]. Science, 2011, 334(6058):928.

[4]. Sridhar H, Meera K S. Study of grid connected solar photovoltaic system using real time digital simulator[C]// International Conference on Advances in Electronics, Computers and Communications. IEEE, 2014:1-6.

[5]. Suampun W. Voltage Stability Analysis of Grid-connected Photovoltaic Power Systems Using CPFLOW [J]. Procedia Computer Science, 2016, 86:301-304.

[6]. Omole A. Voltage Stability Impact of Grid-Tied Photovoltaic Systems Utilizing Dynamic Reactive Power Control[M]. 2010.

[7]. Refaat S S, Abu-Rub H, Sanfilippo A P. Dynamic Voltage Stability Impact of Large-Scale Photovoltaic System on Electric Power Grids[C]// Iet International Conference on Renewable Power Generation. 2016:54 (6. )-54 (6.).

[8]. Yang W, Zhou X, Xue F. Impacts of Large Scale and High Voltage Level Photovoltaic Penetration on the Security and Stability of Power System[C]// Asia-Pacific Power and Energy Engineering Conference. IEEE, 2010:1-5.

[9]. Kabir S, Krause O, Bansal R, et al. Dynamic voltage stability analysis of sub-transmission networks with large-scale photovoltaic systems[C]// Pes General Meeting | Conference \& Exposition. IEEE, 2014:1-5.

[10]. Hill C A, Such M C, Chen D, et al. Battery Energy Storage for Enabling Integration of Distributed Solar Power Generation[J]. IEEE Transactions on Smart Grid, 2012, 3(2):850-857.

[11]. Sugihara H, Yokoyama K, Saeki O, et al. Economic and Efficient Voltage Management Using Customer-Owned Energy Storage Systems in a Distribution Network with High Penetration of Photovoltaic Systems[J]. IEEE Transactions on Power Systems, 2013, 28(1):102-111.

[12]. Yang Y, Li H, Aichhorn A, et al. Sizing Strategy of Distributed Battery Storage System with High Penetration of Photovoltaic for Voltage Regulation and Peak Load Shaving[J]. Smart Grid IEEE Transactions on, 2014, 5(2):982-991.

[13]. Kabir S, Krause O, Haider A. Design of an Optimal Placement Algorithm for Large Scale Photovoltaic in Sub-Transmission Networks[C]// IEEE International Conference on the Developments in Renewable Energy Technology, Icdret. IEEE, 2014:6861669.1-6861669.6. 